\title{
La Real Academia Española y su relación con los encuadernadores de la segunda mitad del siglo XVIII: documentación de archivo
}

\author{
The Royal Spanish Academy and its relationship with the bookbinders
} of the second half of the 18th century: archive documentation

\author{
Alejandro Blázquez MÁRquez (1), Antonio Carpallo Bautista (2) \\ Universidad Complutense de Madrid, alblaz02@ucm.es, acarpall@ucm.es
}

\begin{abstract}
Resumen
Este trabajo tiene como objetivos conocer quiénes fueron los encuadernadores que trabajaron para la Real Academia Española en la segunda mitad del siglo XVIII, identificando el tipo de encuadernaciones, materiales, técnicas de construcción y estado de conservación, número de ejemplares, precios, a quienes iban dirigidas las obras, la relación con otros encuadernadores e impresores, contribuyendo así al conocimiento de la historia de la propia Real Academia y también de la historia de los talleres de encuadernación madrileños y españoles de la última parte del siglo XVIII. En la investigación se ha encontrado documentación de encuadernadores tan relevantes como de Gabriel de Sancha, otros menos conocidos como Ramón Antonio de Herrera, Joaquín Ibarra, los hermanos Miguel y Manuel Millana, y algunos más de los que no teníamos prácticamente noticias como Manuel Serrano, Santiago Torrado, Rafael Sánchez de Aguilera, Hilario Clarós, Jaime Vidal y Román Matute.
\end{abstract}

Palabras clave: Encuadernadores. Libreros. Impresores. Real Academia Española. Documentación de archivo. Siglo XVIII. España.

\section{Introducción}

En el siglo XVIII, imitando las ideas ilustradas francesas traídas por los reyes, se crearon en España una serie de instituciones culturales como la Biblioteca Real Pública en 1712 y las Reales Academias, siguiendo el modelo de las ya establecidas en Francia, como son la Real Academia Española, en 1713, años después la de la Historia en 1738, y la de las Bellas Artes de San Fernando en 1752.

Durante la segunda mitad del siglo XVIII, la Real Academia Española encargó trabajos a un gran número de encuadernadores e impresores dada su creciente producción y demanda de libros. Uno de los más importantes fue Gabriel de sancha, hijo de Antonio de Sancha, y también el impresor Joaquín Ibarra, que además de los grandes trabajos tipográficos realizó encargos de

\begin{abstract}
The aim of this work is to find out who were the bookbinders who worked for the Spanish Royal Academy in the second half of the 18th century, identifying the type of bookbinding, materials, construction techniques and state of conservation, number of copies, prices, to whom the works were addressed, the relationship with other bookbinders and printers, thus contributing to knowledge of the history of the Royal Academy itself and also of the history of the Madrid and Spanish bookbinding workshops in the latter part of the 18th century. The research has found documentation of bookbinders as relevant as Gabriel de Sancha, others less known as Ramón Antonio de Herrera, Joaquín Ibarra, the brothers Miguel and Manuel Millana, and some more of which we had practically no news as Manuel Serrano, Santiago Torrado, Rafael Sánchez de Aguilera, Hilario Clarós, Jaime Vidal and Román Matute.
\end{abstract}

Keywords: Binders. Booksellers. Printers. Royal Spanish Academy. Archival documentation. 18th century. Spain.

encuadernaciones corrientes. También otros encuadernadores fueron contratados mayormente para la realización de encuadernaciones básicas para la venta al por menor como Manuel Serrano, Santiago Torrado, Miguel y Manuel Millana, Rafael Sánchez de Aguilera, Hilario Clarós, Ramón Antonio de Herrera, Jaime Vidal y Román Matute.

Bajo el reinado de Carlos III los libros fueron las herramientas más importantes para promover y aumentar la cultura. Esta circunstancia hizo que en esta época aumentara la producción de libros y que necesitaran ser encuadernados, aumentando también el número de talleres de encuadernación, sobre todo cercanos a la Corte en Madrid (López Serrano, 1945a, 1945b).

La venta de libros durante esta época se componía principalmente de obras de referencia y de moda entre la Corte ilustrada y los Académicos, 
y en menor medida el público ilustrado, aunque este aumentaría radicalmente gracias a las encuadernaciones en rústica y la producción en serie. Dada la ubicación original de las Academias en el centro de la ciudad, el área de la Puerta del Sol se llenó de talleres dedicados a esta labor (López Castán, 1986).

El carácter divulgativo de las obras publicadas por la Real Academia Española hizo que buena parte de las encuadernaciones encargadas para la venta fueran en rústica, en encuadernación holandesa y en pergamino, aunque se fue popularizando el uso de la pasta española, valenciana y jaspeada, con decoraciones de carácter vegetal. El tafilete se reservaba para los obsequios a la Familia Real y a personajes ilustres, como es el caso de las ediciones de lujo y las oraciones preparadas para ocasiones importantes.

Este período dio lugar a ambiciosos proyectos, como la segunda edición del Diccionario, corregido y aumentado, normas de ortografía y gramática para actualizar la Gramática de Nebrija, y la edición del Quijote de 1779.

\section{Estado de la cuestión}

Son limitados los trabajos dedicados a estudiar a los encuadernadores que trabajaron para las Reales Academias. Una de las obras más importantes es la de Vicente Castañeda donde se incluyen pequeñas biografías y anotaciones de algunos encargos de encuadernadores que trabajaron para la Real Academia como Hilario Clarós, Jerónimo Dávila, José Herrera, Joaquín Ibarra, los hermanos Miguel, Manuel y Lorenzo Millana, Antonio de Sancha, y su hijo Gabriel, todos ellos en el siglo XVIII (Castañeda y Alcover, 1958).

Matilde López Serrano, dedicó su vida al estudio de la encuadernación española, sobre la que realizó su tesis doctoral en 1935 en la Universidad Central de Madrid, titulada Encuadernación española en los siglos XVIII y XIX. Fue directora de la Biblioteca de Palacio y destacó como estudiosa, investigadora y gran entusiasta de este arte. Publicó numerosos estudios, entre los que está una serie de artículos dedicados a los encuadernadores bajo los diferentes reinados del siglo XVIII, comenzando por Fernando VI (17461759) (López Serrano, 1940), siguiendo con Carlos III (1759-1788) (López Serrano, 1945a) y Carlos IV (1788-1808), donde nos señalan datos biográficos sobre algunos encuadernadores de la época como Hilario Clarós, Jerónimo Dávila, Ramón Antonio de Herrera, José Herrera, los hermanos Miguel, Manuel y Lorenzo Millana, Gabriel Gómez, Santiago Martín, Santiago Thevin hijo, Félix Ximénez, Tomás Novoa, Bartolomé Ulloa, Manuel Novillo, Ramón Cano, Pascual López,
Román Matute, Juan Antonio Luna, Jaime Vidal, Juan Díaz Vizcaíno, Pedro Bengoechea, entre otros (López Serrano, 1950).

López Serrano también dedica una serie de estudios biográficos a varios encuadernadores, que trabajaron sobre todo para la Real Biblioteca, como Antonio de Sancha, impresor y editor durante el siglo XVIII (Sánchez Espinosa, 2014), siendo el encuadernador oficial tanto en la Real Academia Española como de la Historia y habiendo tenido encargos en la Academia de Bellas Artes de San Fernando (López Serrano, 1946); en otro de los estudios de López Serrano se centra en el encuadernador Gabriel Gómez que trabajó en Madrid durante los reinados de Carlos III, Carlos IV y Fernando VII (López Serrano, 1945c); también dedica un trabajo al Librero-Encuadernador de Cámara, Antonio Suárez Jiménez, considerado el mejor encuadernador del primer tercio del siglo XIX, sobre todo por sus innovaciones en la técnica de los mosaicos, donde utilizaba la pasta valenciana, tipos imperio y catedral para el dorado y barniz para las pieles, siendo el creador de los motivos de cortina (López Serrano, 1942); dedica otro trabajo a Santiago Martín, Encuadernador de Cámara, que ejerció su oficio a finales del siglo XVIII y primer tercio del XIX, destacando en la decoración de guardas y contratapas, así como en el uso de los tipos imperio, cortina y la pasta valenciana jaspeada (López Serrano, 1943); un estudio más lo dedica al encuadernador Pascual Carsí y Vidal, gran defensor del estilo neoclásico en la época de Carlos IV, enviado a Londres, junto a Gabriel Gómez y Gabriel de Sancha, para perfeccionar sus conocimientos de encuadernación, llegando a ser uno de los encuadernadores de la Imprenta Real, obteniendo del rey vivienda y un taller donde tuvo a su cargo varios aprendices trabajando junto a su hermano José (Blas Benito, 1998); para finalizar una monografía centrada en Gabriel de Sancha, hijo de Antonio de Sancha, heredero de la editorial más importante de España, siendo Encuadernador de Cámara con Carlos III (López Serrano, 1975).

Otro trabajo sobre los encuadernadores madrileños del siglo XVIII fue publicado por López Castán (1986), donde hace un repaso al Madrid del siglo XVIIII, sus instituciones, encuadernadores, haciendo hincapié en las Ordenanzas de la Comunidad de Mercaderes y Encuadernadores de libros de la Corte de 1762, en la Compañía de Impresores y Libreros del 1763, y Reales Cédulas como las de 1764, 1778, 1790.

Los pocos trabajos realizados donde se estudian los encargos, anotaciones, cuentas, facturas, etc., referidas a las encuadernaciones los encontramos en la Real Academia de Bellas Artes de San Fernando. Partimos del trabajo desarrollado 
dentro de la tesis doctoral de Yohana Yessica Flores Hernández (2016), donde además de inventariar, catalogar, estudiar y digitalizar más de 650 encuadernaciones artísticas de esta institución, realizó inventario de los encuadernadores que trabajaron para la Real Academia, desde Antonio de Sancha, con la primera nota de 1759, hasta los encuadernadores del siglo XX (Flores Hernández; Carpallo Bautista, 2017).

A partir de esta última publicación se ha continuado con el estudio de esas anotaciones, recibos y facturas de cada uno de los encuadernadores; hasta la fecha están estudiados todos los encuadernadores del siglo XVIII que trabajaron para la Real Academia de Bellas Artes.

Uno de los estudios es el dedicado al impresor Joaquín Ibarra y Marín, que trabajó para la Academia de Bellas Artes desde 1771 hasta 1784; el análisis de la documentación de archivo nos indica que tuvo taller de encuadernación realizando trabajos en pergamino, rústica y pasta (Carpallo Bautista; Flores Hernández; Moro Pajuelo, 2018).

Otro de los encuadernadores estudiados fue $\mathrm{Pe}$ dro Martínez, con recibos entre los años 1794 y 1808 , año en el que muere, según consta en los libros de cuentas del Archivo. Realizó encuadernaciones modestas en piel, pero sin excesivos elementos dorados, muchas de ellas en rústica para documentos como Actas, Estatutos y Distribución de Premios (Carpallo Bautista; Flores Hernández; Burgos Bordonau, 2018).

También trabajó para esta misma corporación el taller de Sancha, desde 1759 hasta 1788 Antonio de Sancha, padre, y desde 1791 hasta 1814 su hijo Gabriel (Flores Hernández; Carpallo Bautista; Burgos Bordonau 2018); durante el periodo de Antonio de Sancha, la Academia le encargó encuadernaciones sencillas de obras para la biblioteca, recubiertas de pergamino, badana, becerro, holandesas sencillas y de puntas y también encuadernaciones en rústica, pudiendo compararse la evolución de los precios de un año para otro, incluso la comparativa de precios que se pagaban al taller de Sancha y los precios, de encuadernaciones similares a otros encuadernadores, siendo más favorable para el taller de Sancha. Se observa también que a Gabriel de Sancha la Academia no le confía la encuadernación de muchas obras, sino que sus encargos se centran en la encuadernación de grandes tiradas de la Relación de Premios, al igual que junto a otros encuadernadores como a Pedro Martínez y Joseph Herrera, incluso en el mismo año.

Uno de esos trabajos está dedicado al librero-encuadernador Francisco de Guzmán, quien trabajó para la Real Academia de Bellas Artes entre los años 1799 y 1800 (Carpallo Bautista; Flores Hernández; Moro Pajuelo, 2019a). Otro estudio realizado versa sobre los encuadernadores Juan Moreno Salgado, quien trabajó entre 1776 y 1777, durante el reinado del rey Carlos III, y el encuadernador José Herrera, activo en la Academia entre 1791 y 1799 , durante el reinado de Carlos IV (Carpallo Bautista; Flores Hernández; Moro Pajuelo, 2019b). El último de los trabajos publicado sobre los encuadernadores de la Academia de Bellas Artes del siglo XVIII nos ofrece información sobre Manuel Millana, activo para la Academia entre 1776 y 1810 (Flores Hernández; Carpallo Bautista; Moro Pajuelo, 2019).

Continuando con los estudios realizados sobre la documentación de archivo de encuadernadores del siglo XVIII, disponemos de uno que nos acerca a los trabajos realizados por la familia Menoyre en la Biblioteca Nacional de España. Esta familia trabajó para la corte de Felipe $\mathrm{V}$ como encuadernadores y también para la Real Librería (García González; Carpallo Bautista; Martín Escudero, 2018).

No podemos olvidar el trabajo realizado en 2018 por Álvaro Espejo Pérez en la Real Academia Española sobre Juan Pérez, el primer encuadernador que trabajó para la Real Academia desde 1724 como librero-encuadernador hasta 1754 , fecha en la que comienzan a trabajar otros encuadernadores como Antonio de Sancha. Mediante el estudio de los datos extraídos de las fuentes primarias del archivo sobre Juan Pérez, se han podido determinar los tipos de encuadernaciones, número de encargos, precios, a quién se regalaban las obras una vez encuadernadas, entre otras, los que nos ayudado a conocer mejor a este encuadernador y la historia de la propia Real Academia, pero sobre todo este encuadernador ha pasado a la historia por ser quien encuadernó y vendió en su tienda el primer Diccionario de la Lengua, impreso entre 1726 y 1739 , por medio del cual hemos podido establecer un corpus de elementos decorativos, lo que nos va a ayudar a la identificación de otras encuadernaciones en otras instituciones (Espejo Pérez; Carpallo Bautista, 2020).

El último estudio que incluimos en este apartado es el publicado por Vicente Castañeda (1934) sobre las notas referentes a los precios de las encuadernaciones desde el siglo XVI al XIX, donde se indica que el tipo de encuadernaciones que se realizaban con mayor frecuencia eran las de papel, pasta regular, pasta fina, tafilete y pergamino; aparecen notas sobre los Millana y sobre todo del taller de Antonio de Sancha, con datos referidos a diversas actas de la Real Academia Española de 1771 sobre la encuadernación del Diccionario en tafilete encarnado, de la 
Gramática en tafilete, además de trabajos realizados por Antonio de Sancha y su hermano Gabriel. Otras notas aparecen en las actas de 1772, $1780,1781,1812$, habiendo en la Academia notas de encargos y trabajos de la familia Sancha hasta 1821, año en que pasa a ser el encuadernador Cayetano Quirós.

\section{Objetivos y metodología}

El presente estudio forma parte de los resultados del Proyecto de investigación I+D (MINECO), titulado "La encuadernación española en la Reales Academias: encuadernadores, talleres y tipologías ligatorias (s. XVIII-XX)" (HAR201783387) (2018-2021). El objetivo es el estudio de los encargos a los encuadernadores que trabajaron para la Real Academia Española durante la segunda mitad del siglo XVIII, consultando los libros de acuerdos, cuentas anuales, anotaciones de conserje y recibos del Archivo. En esta documentación se puede localizar qué tipo de obras se encargaron, a qué encuadernadores, con qué materiales, el costo, y a menudo para quienes estaban destinadas, ya fuera para venta en librerías o para obsequios a personajes ilustres. Los encuadernadores de los que se ha localizado y estudiado su documentación han sido Antonio de Sancha, como encuadernador oficial, Manuel Serrano, Santiago Torrado, Joaquín Ibarra, Gabriel de Sancha, Miguel y Manuel Millana, Rafael Sánchez de Aguilera, Hilario Clarós, Ramón Antonio de Herrera, Jaime Vidal y Román Matute.

Una vez analizada toda la documentación, se procedió a la consulta del catálogo de la Biblioteca para localizar las obras encontradas en la documentación. Una vez halladas las referencias disponibles, se analizaron in situ todas las encuadernaciones, realizando una descripción de los materiales empleados, técnicas de construcción, técnicas y elementos decorativos y estado de conservación, además de digitalizarse las encuadernaciones y los detalles decorativos como hierros, guardas y marcas de propiedad, lo que nos permitió crear un corpus de hierros de cada taller.

\section{Fuentes}

En cuanto a las fuentes primarias hemos trabajado con la documentación propia generada por la Real Academia Española, que se custodia en su propio Archivo. La fuente de información más importante y relevante han sido los libros cuentas, relativos desde 1754 hasta el año 1799. Mediante esta documentación se ha podido averiguar el número de ejemplares que se encuadernó de cada obra, así como sus precios según los tipos de encuadernaciones realizados; también se han podido conocer los precios de las impresiones, y además los detalles de los proyectos de la segunda edición del Diccionario y el proyecto del Quijote de 1779.

Otro tipo de documentación revisada han sido los libros de actas-llamados de Acuerdos-, donde se refleja la actividad del día a día de los académicos en la Academia, el trabajo que realizaban, las relaciones con otras instituciones y las personales de los académicos, así como detalles generales de los encargos realizados, que se muestran con más detalle en las cuentas y recibos; esta documentación ha permitido conocer el destino de muchas de las encuadernaciones.

Por último, las propias encuadernaciones nos han brindado un abundante conocimiento de los materiales empleados, técnicas constructivas y decorativas, utensilios utilizados y el estado de conservación de cada ejemplar.

Respecto a las fuentes secundarias hemos utilizado diversos artículos y publicaciones científicas, todas ellas referenciadas en el epígrafe sobre el estado de la cuestión.

\section{Encuadernadores}

A continuación estudiamos los diferentes encargos y vinculaciones que han tenido los siguientes once encuadernadores con la Real Academia Española en la segunda mitad del siglo XVIII.

\subsection{Manuel Serrano}

La información biográfica de que disponemos de este encuadernador es escasa teniendo solo menciones a los cuatro encargos que había tenido en la Academia entre 1755 y 1758.

El primero de los encargos tiene como documentación el recibo de este encuadernador del 7 de abril de 1755 cuando recibió el pago de seis juegos del Diccionario a 6 rsvn cada tomo, seis Ortografías a 2 rsvn y cuatro Gramáticas de Nebrija a 3 rsvn, todos en pergamino, por un total de 240 rsvn, de los cuales recibió 180 rsvn y un sexto tomo del Diccionario como obsequio. El segundo de los pagos lleva por fecha el 21 de febrero de 1757 recibió 36 rsvn por encuadernar un juego de Diccionario en pergamino con cartón para el académico Pedro de Campomanes. El tercer apunte lleva por fecha el 8 de marzo de 1758 cuando recibió 2 rsvn por reencuadernar la Gramática de $\mathrm{Ne}$ brija de la Academia en $4^{\text {a }}$, y 36 rsvn por un juego de Diccionario para Juan de Santander. El cuarto y último recibo los encontramos con fecha del 1 de octubre de 1758 cuando percibió $41^{\text {rsvn }}$ por un juego de Diccionario, una Gramática de Nebrija y una Ortografía, todos en pergamino con su cartón. Durante los años de relación con la Academia llegó a encuadernar sesenta y siete 
volúmenes en su mayoría sobre pergamino con cartón, tipo de encuadernación al de llamamos "a la romana".

\subsection{Santiago Torrado}

De este encuadernador desconocemos datos biográficos y solo tenemos la información encontrada en la documentación del Archivo sobre el encargo que tuvo en 1761 y del que tenemos el recibí del cobro con fecha del 3 de mayo (2) cuando recibió $66^{\text {rsvn }}$, de los cuales $36^{\text {rsvn }}$ eran de los seis tomos del Diccionario en pergamino avitelado, y 30 rsvn por la encuadernación de tres tomos del Diccionario de la Crusca (3), y de añadir el tejuelo en tafilete en los seis volúmenes del Diccionario.

\subsection{Joaquín Ibarra y Marín}

Fue uno de los impresores más relevantes de la segunda mitad del siglo XVIII aunque también tuvo taller de encuadernación donde realizó trabajos austeras para la Academia, al igual que para la de Bellas Artes. Nacido en Zaragoza el 19 de julio de 1725, estudió Humanidades en la Universidad de Cervera, donde su tío Manuel Ibarra era impresor y encuadernador, de quien aprendió el oficio.

En 1754 se trasladó a Madrid, donde instaló su taller, primero en la calle de las Urosas, y luego en la de la Gorguera. Aunque sabía y tenía un obrador de encuadernación, casi siempre delegaba a otros talleres dicha tarea, obedeciendo así las normas de la Imprenta Real y la Compañía de Libreros del Reino.

Durante su carrera se ganó la protección y la estima de las Reales Academias - siendo nombrado por la Real Academia Española como su Impresor en 1779-, del Ayuntamiento de Madrid y del rey Carlos III. Imprimió el Salustio, y la edición del Quijote de 1779 en cuatro volúmenes, entre otras muchas obras de la Real Academia Española.

De su primer matrimonio tuvo dos hijos, Joaquín y Joaquina, y de su segundo con Manuela Contrera, tuvo una hija llamada Manuela. A su muerte y tras grandes discrepancias, viuda e hija se quedan con la imprenta.

Murió en Madrid el 13 de noviembre de 1785, a los 60 años. La Real Academia Española, entre otras instituciones, mostró sus condolencias por su muerte, sufragando cincuenta misas por su alma, como se hacía con los Académicos de Número. La imprenta continuó bajo el nombre de viuda de lbarra, que llevó con su hija, llevando a cabo los encargos de sus clientes habituales.
En la Academia hemos encontrado cinco recibos de cobro entre 1771 y 1779 . El primero tiene la fecha del 5 de diciembre de 1771 cuando recibió 2.798 rsvn y 4 mrs por la impresión y encuadernación de la Oración por el nacimiento del Infante Carlos Clemente de Borbón, de los cuales 342 rsvn fueron por encuadernar seiscientos ochenta y cuatro ejemplares en papel jaspeado a medio real cada una, 480 rsvn por ocho ejemplares en tafilete a 60 rsvn, $84{ }^{\text {rsvn }}$ por seis ejemplares en pasta ornamentados con una orla dorada a 14 rsvn, y 940 rsvn por noventa y cuatro ejemplares en pasta "Figura 1." a 10 rsvn cada uno, haciendo un total de setecientos noventa y dos ejemplares.
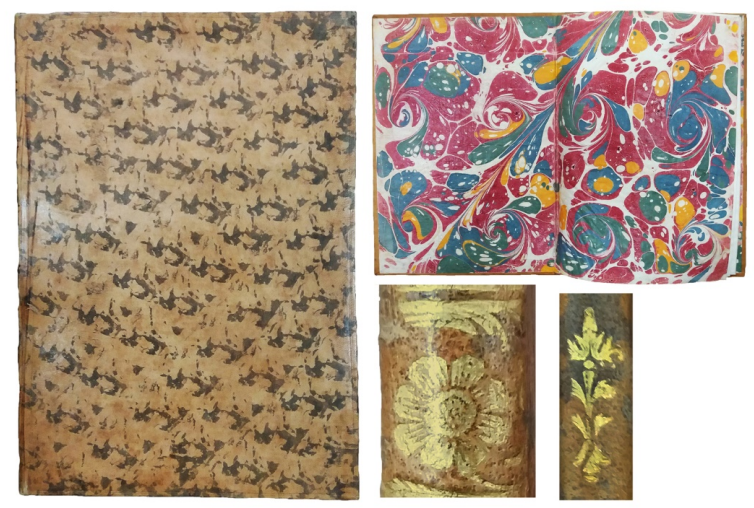

Figura 1. Encuadernación en pasta jaspeada (Sig. Sala Exp.)

Con fecha del 26 de enero de 1774 (4) encontramos el segundo recibí por la cantidad de 10 rsvn por encuadernar dos tomos del Diccionario. El 3 de abril de 1777 (5) recibió su tercer cobro por la cantidad de 2.110 rsvn habiendo realizado la impresión y encuadernación del Sermón de Honras de Fernando de Silva Álvarez de Toledo, duque de Alba y director de la Real Academia Española muerto en 1776, de los cuales 500 rsvn fueron por la encuadernación en papel pintado. El cuarto recibo tiene por fecha el 22 de septiembre de 1778 (6) cuando Ibarra recibió 2.020 rsvn por la impresión y encuadernación de las ediciones económicas de los Cantos de Cortés, de los cuales 225 rsvn fueron por cuatrocientos cuarenta en papel jaspeado a medio real cada uno, y $346{ }^{\text {rsvn }}$ y 16 mrs por novecientos cincuenta en blanco. El último de los encargos que tubo Ibarra de la Academia fue abonado el 1 de julio de 1779 (7) mediante un recibo de 18 rsvn por la encuadernación de un "papel de Ortega" y $14{ }^{\text {rsvn }}$ por encuadernar en tafetán una poesía premiada para el duque de Monteleón (8), tal y como se indica en la documentación.

La producción encuadernadora de Ibarra la podemos resumir en dos mil ciento ochenta y seis 
encuadernaciones, en su mayoría con cubierta de papel jaspeado y en blanco, además de ejemplares en pasta, con orlar doradas, en tela de seda (tafetán).

\subsection{Rafael Sánchez de Aguilera}

El investigador Vicente Castañeda (1958) cuenta que fue compañero de Ibarra en su taller, y que a su muerte fue nombrado regente del taller de la Viuda de lbarra; actuó en la dirección del taller de Ibarra entre 1753 y 1785, año de la muerte del impresor; enseñó las artes de la encuadernación a Miguel de Burgos.

En la Real Academia hemos localizado varios documentos que hacen referencia a este encuadernador.

En el primero, con fecha del 20 de diciembre de 1794 (9), se indica que Rafael Sánchez entregue a Mauricio Cano dos Gramáticas castellanas a 9 ${ }^{\text {rsvn }}$ cada una, dos Orthographias a $8{ }^{\text {rsvn }}$ cada una, dos Quijotes chicos a $72{ }^{\text {rsvn }}$ cada uno, otros dos "compendios del diccionario" a $98{ }^{\text {rsvn }}$ cada uno y dos Diccionarios grandes (tres tomos) a 224 rsvn cada uno de los dos juegos, todo ellos encuadernados en pasta, para Juan de Sahagún de la Mata Linares, I conde del Carpio (10) y Clemente Peñalosa (11).

Ya en el año 1795, con fecha del 17 de marzo (12), localizamos otros documentos donde se indica que se entregue a Mauricio Cano una Gramática castellana a 9 rsvn, una Orthographia a 8 rsvn, un Quijote chicos a $72^{\text {rsvn }}$ cada uno, un "compendio del diccionario" a 98 rsvn y tres tomos del Diccionario grande a $224{ }^{\text {rsvn }}$, todo ellos en pasta, para el académico honorario Juan de Flores (13). Con fecha del 23 de octubre de 1795 (14), Rafael Sánchez de Aguilera solicita a Juan Crisóstomo Ramírez (15) que envíe a casa de la viuda de lbarra treinta Diccionarios para que puedan ser vendidos. Unos días más tarde, con fecha del 6 de noviembre (16), Rafael Sánchez de Aguilera solicita a Juan Crisóstomo Ramírez que envíe a casa de la viuda de lbarra cuatro paquetes con sesenta Diccionarios para que sean encuadernados en pasta y pergamino, y algunos solo en rama, para que puedan ser vendidos. Con fecha del 21 de noviembre (17) de ese año, de nuevo otra carta de Rafael Sánchez a Juan Crisóstomo, solicitando que envíe a la imprenta de la viuda de Ibarra treinta Diccionarios, un paquete de Gramáticas tamaño marquilla, otro paquete de Orthographias, en papel regular, y por último un juego de estampas del Quijote con letrero. La última nota de este año corresponde al 16 de diciembre (18) Conde Rafael Sánchez solicita le envíen a la imprenta treinta Diccionarios.
Del año 1796 hemos localizado, con fecha del 8 de enero (19), una carta solicitando el encuadernador que le envíen a la imprenta de lbarra, gestionada por su viuda Manuela Contera (20), treinta Diccionarios y doscientas Orthographias. Con la misma fecha del 8 de enero (21) encontramos una carta de Rafael Sánchez a Juan Crisóstomo remitiendo ciento cincuenta ejemplares de marquilla de la cuarta edición de la Gramática castellana. En otro documento, con fecha del 21 de enero (22), indica Juan Crisóstomo que se entreguen al portador treinta Diccionarios y cien juegos del Quijote pequeño, para la venta en la librería de Manuela Contera. Con fecha del 8 de febrero (23), localizamos otra carta donde se solicitan que se envíen sesenta Diccionarios en cuatro paquetes. De nuevo, desde la Casa de Manuela Contera, con fecha del 9 de marzo (24), se solicita que se envíen treinta Diccionarios y un paquete de Orthographias para su venta. Con fecha del 2 de abril (25) localizamos otra carta donde se solicitan, por parte de la librería de la viuda de Ibarra, treinta Diccionarios y cien juegos del Quijote, indicándose que solo se entregaron los Diccionarios y veinte juegos del Quijote pequeño. En otro documento, con fecha del 20 de septiembre (26) de ese mismo año 1796, se indica a Juan Crisóstomo entregue al portador veinte Diccionarios para encuadernar en casa de Rafael Sánchez, aunque realmente se entregaron treinta ejemplares.

En la Academia hemos localizado solo un recibo con fecha del 7 de febrero de 1797 (27) donde se indica que cobró la cantidad de 612 rsvn por las encuadernaciones de seis juegos del Quijote grande; según se indica en la documentación, por pasar por el tórculo cada juego el coste fue de 12 rsvn por cada uno; el coste de la encuadernación - por el precio se presume que fue por una encuadernación en pasta, a 22,5 rsvn el tomo- terminó siendo a 90 rsvn el juego.

\subsection{Gabriel de Sancha Sanz}

Gabriel de Sancha nació el 18 de marzo de 1746 en Madrid, primogénito de Antonio de Sancha y Gertrudis Sanz, y murió en Madrid en 1820. Fue uno de los encuadernadores más relevantes de finales del siglo XVIII y primeros del siglo XIX. Fue educado de forma esmerada por su padre, encauzándolo hacia las artes del libro con el objetivo de que continuara la empresa, aprendiendo francés, dibujo y literatura.

En 1760, Gabriel acompañó a su padre Antonio en su segundo viaje a París, para aprender el arte de la encuadernación. Poco después, recibió una pensión de Carlos III para permanecer en la 
ciudad parisina, siendo en ese momento la capital europea de la encuadernación.

Progresó con rapidez, ya que en 1766 se le nombró Encuadernador de Cámara. En el taller de Sancha encontramos numerosos hierros, composiciones de origen francés y en las encuadernaciones observamos técnicas empleadas por los encuadernadores reales de la talla de Padeloup, Derôme, Le Monnier y Dubuisson (López Serrano, 1976). Gabriel viajó frecuentemente a París hasta 1783.

Antonio de Sancha concertó un matrimonio con Manuela Moreno, hija del grabador Juan Manuel Moreno, amigo y colaborador. El matrimonio se celebró en 1788 y del que nacieron dos hijos, Indalecio, que heredó el taller, y Estefanía (López Serrano, 1946).
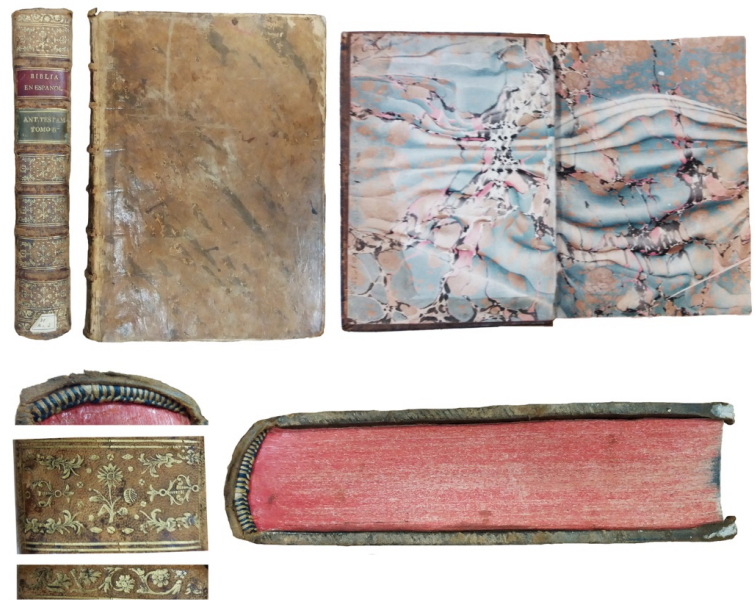

Figura 2. Encuadernación en pasta española (Sig. Sala Coms. 31-A-1 al 5)

A la muerte de su padre, Gabriel heredó casi todos sus bienes, pero también sus problemas. La Enciclopedia Metódica, ambicioso proyecto fracasado de su padre, hizo llevar a una situación preocupante al taller debiéndose trasladarse a un local más modesto en la calle del Lobo y su vivienda a Concepción Jerónima. Continuó trabajando con su hermano Antonio, quien le lega todos sus bienes a su muerte en 1818. Gabriel murió el 13 de marzo de 1820 , teniendo serios problemas económicos, debido principalmente a los lastres que le legó su padre.

El principal problema para identificar sus encuadernaciones antes de la muerte de su padre es que en esa época no siempre se firmaban las encuadernaciones, con lo que desconocemos qué tipo o cuáles fueron los trabajos realizados mientras compartía taller con Antonio. Ya a partir de 1790 sabemos que las encuadernaciones fueron realizadas por él, además de que en muchas de ellas añadía en el lomo en anagrama GS.

En la Real Academia Española hemos encontrado un recibo con fecha del 10 de marzo de 1792 (28) donde se indica que Gabriel cobró la cantidad de $3.777^{\text {rsvn }}$ por cuatro tomos en pasta de Cicerón a 7 rsvn , una encuadernación en pasta de la obra Examen de la posibilidad de fixar la significacion de los sinónimos... (29) a 5 rsvn, cuatro tomos del Diccionario de Gattel (30) en pasta en $4^{\circ}$ a 29,5 rsvn, cinco tomos de Biblia en castellano en pasta (31) "Figura 2." tamaño folio a 14 rsvn, diez Diccionarios en tafilete a $140{ }^{\text {rsvn }}$ cada uno, treinta en pasta española, también llamada de árbol, a 36 rsvn, y noventa y dos en pasta a 18 rsvn, junto a dos cajones a 20 rsvn, y otros 20 rsvn por arcas del agua. En total Gabriel realizó un total de ciento cuarenta y seis volúmenes encuadernados, muchos de ellos en pasta jaspeada y pasta española.

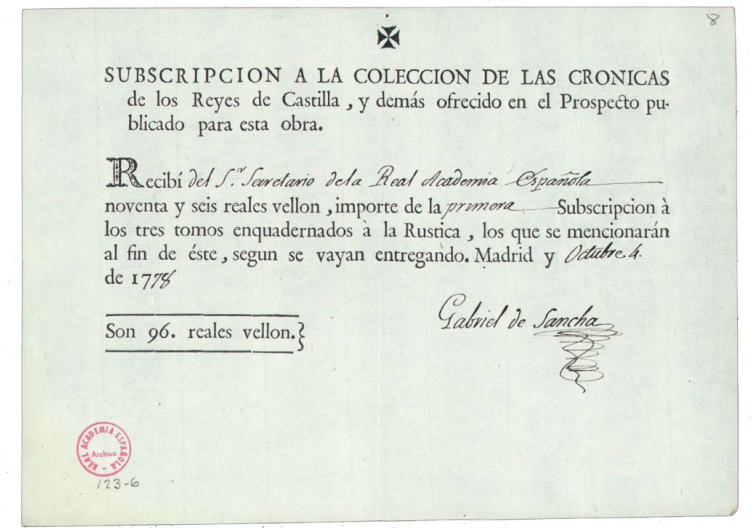

Figura 3. Suscripción a la colección de Crónicas... por Gabriel de Sancha en 1778 (Sig. 123/6/8/1v)

También con fecha del 4 de octubre de 1778 localizamos un recibo donde se indica el pago de 96 rsvn, por parte del Secretario de la Academia, por la suscripción a los tres tomos encuadernados en rústica de la colección de Crónicas de los Reyes de Castilla "Figura 3." (32).

\subsection{Miguel y Manuel Millana}

Miguel, Manuel y Lorenzo Millana fueron libreros encuadernadores a los que se encomendó la venta de las publicaciones de la Real Academia Española tras la muerte de Antonio de Sancha. Tuvieron obrador y librería en la calle de la Zarza en 1789, en la calle del Correo viejo entre 1791 y 1794 , año en que se traslada a la calle Preciados, $\mathrm{n}^{\circ} 3$. Miguel Millana murió en 1797, efectuando diversos encargos como Gramáticas, Quijotes, etc. Manuel Millana, que murió en 1812, es de los tres hermanos el más reconocido dentro del arte de la 
encuadernación, siendo Librero-encuadernador de la Real Academia y entregando encargos a partir de 1790, como ediciones cuidadas y modestas de Diccionarios, Ortografías y Premios de la Real Academia (López Serrano, 1950; Flores Hernández; Carpallo Bautista; Moro Pajuelo, 2019).

Los hermanos Millana trabajaron para la Real Academia de Bellas Artes de San Fernando entre 1776 y 1810 y en la documentación de Archivo de la Real Academia Española hemos localizado recibos entre 1796 y 1799, aunque sabemos que continuaron trabajando para la Academia durante princpios del siglo XIX.

Con fecha del 28 de octubre de 1795 (33) los académicos Juan Crisóstomo Ramírez Alamanzón y Pedro de Silva y Sarmiento de Alagón (34) realizaron un informe sobre diversos aspectos de los arreglos que debían realizarse en la nueva sede de la Academia en la calle de Valverde. Entre esas recomendaciones se indica que se debe reservar una habitación de la nueva ubicación para el despacho de las obras de la Academia, gestionada por un Librero, que se venderán con diversas encuadernaciones como en pasta, pergamino o solo en papel y que se le sacarán mensualmente del almacén. Se indica también que el librero deberá encuadernar todas las obras de la Academia así como las que se le encarguen y destinen para la venta al público, pagándosele por parte de la Academia a unos precios equitativos según los tipos de encuadernaciones; deberá tener un diario con las ventas realizadas, teniendo que entregar las cuentas al Académico Bibliotecario cada semana. Se le recompensará suficientemente con cuatro ${ }^{\text {rsvn }}$ cada día y una habitación como vivienda, quedando suprimido así el tres por ciento de comisión por las ventas. Se indica también que si tuviera tiempo realizara encuadernaciones para particulares. Los autores del informe recomiendan a un librero joven como Miguel Millana, que en esos momentos vivía en la calle de la Zarza; el informe también indica que la Academia podrá tomarse el tiempo que estime oportuno para la elección y que una vez decidido quién será el librero elegido, no es necesario que se traslade inmediatamente a la sede de la Academia hasta haber visto el estado de las cuentas con la casa de Ibarra. De todas formas se indica que si urge, se pondrá a encuadernar Gramáticas, para la venta, con anuncios en la Gaceta y para regalar.

El primero de los recibos es de finales de 1796 (35) (Figura 4) cuando recibió 888,5 rsvn por la realización de veinticuatro carteras de piel a 1,5 rsvn, además de la encuadernación de obras para la Academia como dieciocho Gramáticas en tafilete a $25^{\text {rsvn }}$, otras treinta en pasta regular a 4 rsvn, un juego de seis tomos del Quijote a $3^{\text {rsvn }}$ el tomo, nueve Gramáticas pequeñas a 2,5 rsvn, dos más de papel de marquilla a $4{ }^{\text {rsvn }}$, veinticuatro más de papel de marquilla recubierta de pasta fina a 6 rsvn, y treinta más de papel regular recubierta en pasta fina a 3 rsvn.

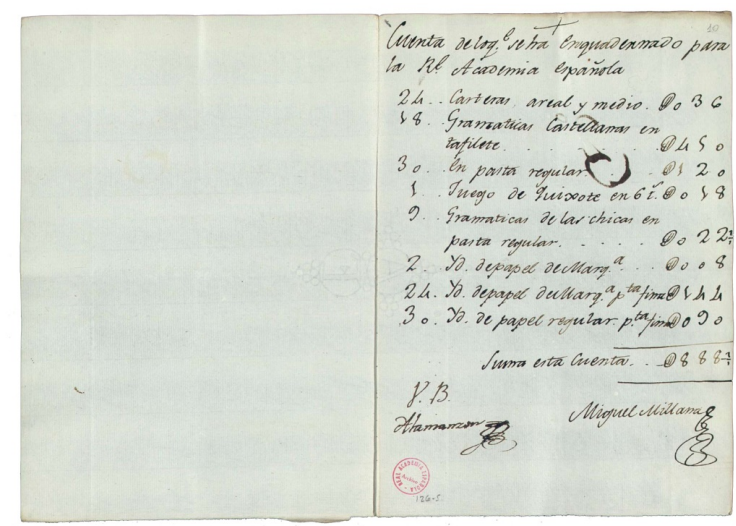

Figura 4. Recibo de Miguel Millana de finales de 1796 (Sig. 126/5/10/2r)

En los siguientes diez encargos al taller de Millana encontramos que el encuadernador realizó un descuento de un $10 \%$. El primero de estos recibos lleva fecha del 30 de diciembre de 1797 (36) donde se incluye un recibí de 3.496 rsvn por doscientas Ortografías en pasta a 2,5 rsvn, ciento veinte Gramáticas en pasta "Figura 5." (37) a 3 rsvn, sesenta Diccionarios en $8^{\circ}$ a $18^{\text {rsvn }}$, y cuarenta y siete juegos de Quijote a 24 rsvn el juego. El 31 de diciembre (38) recibió 1.570 rsvn por once Diccionarios en pasta, seis a $16{ }^{\text {rsvn }}$ y cinco a 18 rsvn, además de uno en pergamino a 8 rsvn, quince Quijotes chicos, tres juegos a 22 rsvn, doce a 24 rsvn, además de dos en pergamino a $12^{\text {rsvn, ciento }}$ cinco Gramáticas en pasta a $3{ }^{\text {rsvn }}$ y seis en pergamino a un rsvn, doscientas Ortografías en pasta a $2,5^{\text {rsvn }}$ y ciento veintiuno de pergamino a un ${ }^{\text {rsvn }}$, finalizando el año con cuarenta y tres Suplementos modernos a la rústica a 2 rsvn.

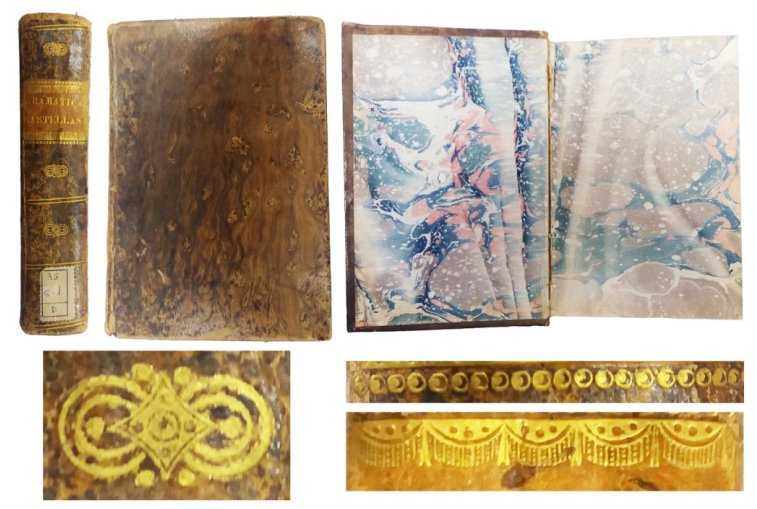

Figura 5. Encuadernación en pasta española (Sig. 35-6-1 Dup.) 
Manuel Millana recibió, el 26 de abril de 1798 (39), la cantidad de $3.725^{\text {rsvn }}$ por cinco juegos del Quijote en $8^{\circ}$ mayor a $30^{\text {rsvn }}$, setenta y cinco Diccionarios a $18^{\text {rsvn }}$, ciento veinte Gramáticas a 3 rsvn, y noventa y cinco juegos del Quijote en $8^{\circ}$ con papel regular a 24 rsvn. El 30 de junio (40) recibió $1.215^{\text {rsvn }}$ por setenta y cinco Diccionarios a 18 rsvn cada uno. También de ese mismo año, el 29 de julio (41) recibió $668^{\text {rsvn }}$ por cuatro juegos de Quijote en folio a 100 rsvn, dos juegos de Quijote de pasta en $8^{\circ}$ a 24 rsvn, y quince Diccionarios a 18 rsvn. El último apunte de este año 1798 es del 14 de octubre (42) cuando recibió 972 rsvn por sesenta Diccionarios a $18^{\text {rsvn }}$ cada uno.

El último año corresponde a 1799 , con un recibo del 6 de enero (43) donde se indica el cobro de 1.269 rsvn por setenta y cinco Diccionarios a 18 rsvn, y treinta pares de carteras a 2 rsvn cada una. El 20 de julio (44) recibió su segundo pago de ese año por la cantidad de $2.826{ }^{\text {rsvn }}$ por doscientas cuarenta Gramáticas a 3 rsvn, un juego del Quijote chico, ornamentado con una orla dorada, a 30 rsvn y cuarenta y cuatro juegos sin orla a 24 rsvn; finalizando el recibo con treinta Diccionarios a 18 rsvn, y doscientas Ortografías a 2,5 ${ }^{\text {rsvn. }}$. El tercer pago de ese año corresponde al 18 de septiembre (45) con un recibo de 486 rsvn por la encuadernación de treinta Diccionarios a $18^{\text {rsvn }}$ cada ejemplar. El último recibo tiene fecha del 8 de diciembre (46) cuando Millana recibió 783 rsvn por treinta Diccionarios a 18 rsvn cada volumen, cien colecciones de premios en pasta a 3 rsvn cada ejemplar y cuarenta en rústica a 0,75 rsvn.

Después de observar y analizar los encargos y pagos realizados a Manuel Millana encontramos que realizó un gran número de encuadernaciones, sobre todo de Diccionarios, Gramáticas y Quijotes, elaborando ciento diecinueve encuadernaciones en 1796, mil ciento sesenta en 1797 , quinientas cincuenta y siete en 1798 y seiscientas treinta y cinco en 1799 , haciendo un total de dos mil cuatrocientas setenta y una encuadernaciones junto a la elaboración de carteras de piel.

\subsection{Hilario Clarós}

Fue un librero-encuadernador, cuñado de los Millana, cuyo taller estuvo en la calle Arenal y recibió encargos de la Real Academia Española y de la Biblioteca Real Pública. Fue además LibreroEncuadernador de Palacio (López Serrano, 1950). En la documentación del Archivo de la Real Academia Española se han encontrado numerosos encargos en un periodo de tiempo muy breve, sobre todo de Diccionarios, Gramáticas y Ortografías destinadas para la venta. Sus trabajos en esta centuria se centran entre 1797 y 1799.
El primer recibo tiene por fecha el 30 de diciembre de 1797 (47) por el pago de 504 rsvn para realizar quince Diccionarios en folio a 8 rsvn el tomo, diez Quijotes de seis tomos a $2{ }^{\text {rsvn }}$ el tomo, ciento veinte Gramáticas $8^{\circ}$ a un ${ }^{\text {rsvn }}$, y doscientas Ortografías $8^{\circ}$ a un rsvn, todo con una terminación recubierta en pergamino.

Del año 1798 encontramos varios recibos, el primero del 28 de abril (48) donde recibió 396 rsvn por quince Diccionarios en folio a $8{ }^{\mathrm{rsvn}}$ el tomo, ciento veinte Gramáticas $8^{\circ}$ a un ${ }^{\text {rsvn }}$, y doscientas Ortografías $8^{\circ}$ a un ${ }^{\text {rsvn }}$, todo de nuevo en pergamino. El segundo recibo es del 1 de agosto (49) cuando recibió 396 rsvn por quince Diccionarios en folio a 8 rsvn el tomo, ciento veinte Gramáticas $8^{\circ}$ a un rsvn, y doscientas Ortografías $8^{\circ}$ a un ${ }^{\text {rsvn }}$, todo también en pergamino, es decir un encargo similar al del 28 de abril. El 4 de octubre (50) Hilario Clarós cobró su tercer recibo del año por la cantidad de $288^{\text {rsvn }}$ por ciento veinte Gramáticas $8^{\circ}$ a un ${ }^{\text {rsvn }}$, y doscientas Ortografías $8^{\circ}$ a un ${ }^{\text {rsvn }}$, todo en pergamino. El último recibo de 1798 tiene fecha del 24 de diciembre (51) cuando recibió 394 rsvn por quince Diccionarios en folio a 8 rsvn el tomo, ciento veinte Gramáticas $8^{\circ}$ a un rsvn, y ciento noventa y ocho Ortografías $8^{\circ}$ a un rsvn, todo en pergamino.

Finalizamos los encargos de Hilario Clarós en los recibos de 1799 , siendo el primero que hemos localizado con fecha del 7 de abril (52) recibió 396 rsvn de nuevo por quince Diccionarios en folio a 8 rsvn el tomo, ciento veinte Gramáticas $8^{\circ}$ a un rsvn, y doscientas Ortografías $8^{\circ}$ a un ${ }^{\text {rsvn }}$, todo en pergamino. El segundo recibo es del 29 de mayo (53) cuando recibió 216 rsvn por doscientas cuarenta Gramáticas $8^{\circ}$ a un ${ }^{\text {rsvn }}$, todo en pergamino. El segundo pago lo vemos reflejado en el recibí del 6 de julio (54) por la cantidad de $486{ }^{\text {rsvn }}$ por treinta Diccionarios en folio a 18 rsvn, todo en pergamino. El último de los recibos tiene la fecha el 29 de octubre (55) por la cantidad de $288^{\text {rsvn }}$ por ciento veinte Gramáticas $8^{\circ}$ a un ${ }^{\text {rsvn }}$, y doscientas

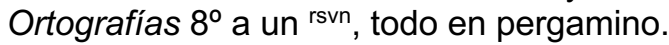

La producción de Hilario Clarós es muy importante sobre todo en Gramáticas, Diccionarios y Ortografías, todo ello realizado en pergamino. Durante el año 1797 realizó trescientas noventa y cinco encuadernaciones, en 1798 elaboró mil trescientas veintitrés y en 1799 novecientas veinticinco, haciendo un total entre los tres años de dos mil seiscientas cuarenta y tres encuadernaciones.

\subsection{Ramón Antonio de Herrera}

Trabajó bastante para el Palacio, donde siguiendo la influencia inglesa de la encuadernación, ornamenta los lomos con rosetas, 
floroncillos, pequeñas flores, decorando las tapas con unas orlas de festones junto a hilos dorados. Realizó numerosas encuadernaciones con pasta española con ornamentaciones sencillas mediante ruedas. Firmaba sus obras con un monograma personal dentro de un óvalo o círculo (López Serrano, 1950).

En la documentación del Archivo de la Academia hemos localizado dos encargos de encuadernaciones, el primero lleva por fecha el 26 de marzo de 1798 (56) cuando Herrara recibió 414 rsvn por la encuadernación de seis tomos del Quijote en $8^{\circ}$ en pasta a $24^{\text {rsvn }}$ cada uno, y por quince Diccionarios en pasta a 18 rsvn cada uno. $Y$ ese mismo año, el 13 de julio (57) recibió 810 rsvn por cuarenta y cinco Diccionarios a $18^{\text {rsvn }}$ cada uno. Su relación con la Academia durante el siglo XVIII no fue muy amplia aunque llegó a encuadernar sesenta y seis volúmenes de Diccionarios y Quijotes en pasta.

\subsection{Jaime Vidal}

Jaime Vidal trabajó para la Biblioteca Real Pública y para la Real Academia Española realizando encuadernaciones en tafilete y pasta (López Serrano, 1950). En la Academia hemos localizados dos encargos durante el siglo XVIII, en concreto en 1798. El primero es del 4 de julio (58) cuando recibió 810 rsvn por cuarenta y cinco Diccionarios a $18^{\text {rsvn }}$ cada uno. El segundo del 11 de diciembre (59) cuando recibió $360{ }^{\text {rsvn }}$ por ciento veinte Gramáticas a $3^{\text {rsvn }}$ cada una. Observamos que la relación de este encuadernador con la Academia durante esta centuria fue breve aunque pudo realizar la encuadernación de ciento sesenta y cinco ejemplares del Diccionario y de la Gramática, con unos precios similares a los ofrecidos por otros encuadernadores contemporáneos como Matute, Herrera, Clarós o Millana.

\subsection{Ramón Matute}

Trabajó para la Academia durante el siglo XVIII mediante tres encargos entre 1798 y 1799 , teniendo el primero el 2 de agosto de 1798 (60) cuando recibió $1.378^{\text {rsvn }}$ por doce juegos del Quijote a 24 rsvn el juego, treinta Diccionarios en pasta a $18^{\text {rsvn }}$, cien Ortografías a 2,5 ${ }^{\text {rsvn }}$ y otras cien Gramáticas a $3{ }^{\text {rsvn. }}$. El segundo ya lo encontramos con fecha de 1799, del 14 de abril (Fig. 8) (61) cuando recibió $397,5^{\text {rsvn }}$ por ochenta y siete Ortografías a 2,5 rsvn, un Vocabulario marino en folio a $12^{\mathrm{rsvn}}$, siete Diccionarios a $18^{\mathrm{rsvn}}$, y seis tomos de Premios de la Academia "Figura 6." (62) a $7^{\text {rsvn }}$.

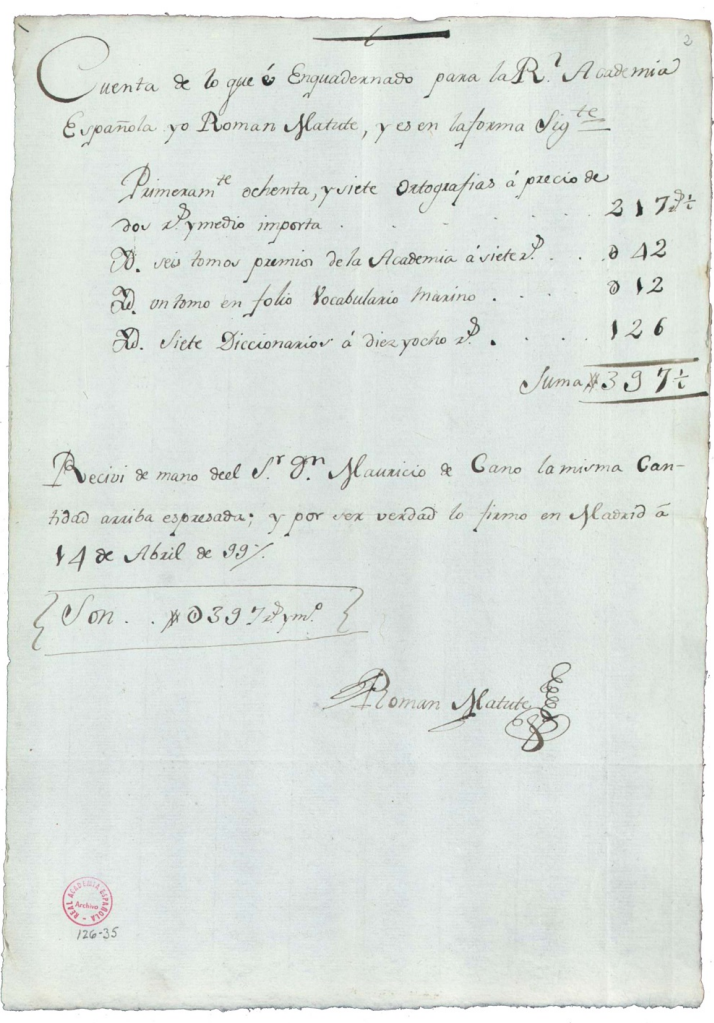

Figura 6. Recibo de Ramón Matute de abril de 1799 (Sig. 126/35/2/1r)

El tercer encargo lleva por fecha el 4 de agosto (63) con un pago de $1.476{ }^{\text {rsvn }}$ por veinticuatro juegos del Quijote en pasta en $8^{\circ}$ a $4{ }^{\text {rsvn }}$ el tomo, ciento veinte Gramáticas a 3 rsvn, y treinta Diccionarios en pasta a $18^{\mathrm{rvn}}$. Su producción durante finales del siglo XVIII fue sobre todo para la encuadernación de Quijotes, Diccionarios, Ortografías, Gramáticas y Premios de la Academia, con tiradas en muchos casos de más de cien lo que hace que en total encuadernara en este periodo seiscientas sesenta y siete ejemplares, la mayor parte de ellos en pasta "Figura 7.".

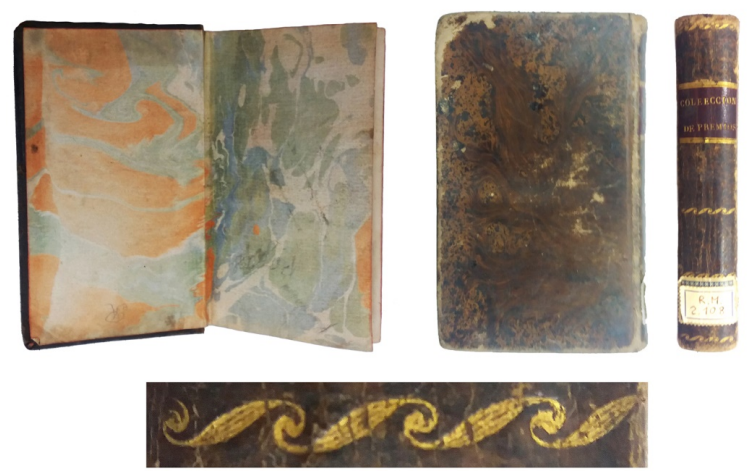

Figura 7. Encuadernación en pasta española (Sig. RM-2108) 


\section{Resultados}

La consulta de las documentación del Archivo de la Academia y posteriormente la localización de varias de las encuadernaciones reseñadas en la documentación referidas a cada encuadernador, nos ha ayudado a reconstruir cronológicamente la relación de la Academia con un grupo de encuadernadores madrileños, algunos conocidos como Gabriel de Sancha, los hermanos Millana, Ramón Antonio Herrera, Joaquín Ibarra, aunque su faceta de encuadernador también ha sido poco estudiada, pero otros totalmente desconocidos como Manuel Serrano, Santiago Torrado, Rafael Sánchez de Aguilera, Hilario Clarós, Jaime Vidal y Ramón Matute.

Muy posiblemente algunos de ellos continuaran trabajando para la RAE durante los primeros años del siglo XIX, ya que la documentación encontrada hace referencia a los últimos años del siglo XVIII, en concreto Ramón Matute entre los años 1798 y 1799, Jaime Vidal y Ramón Antonio de Herrara sus encargos son del año 1798, Hilario Clarós tienen numerosos encargos entre 1797 y 1799, Rafael Sánchez de Aguilera un solo encargo en 1797, los hermanos Millana con importantes encargos entre 1796 y 1799. De Gabriel de Sancha solo hemos localizado un recibo de 1792 lo que nos hace pensar que la Academia no colaboró con él en los años sucesivos aunque muera en 1820. El resto de encuadernadores trabajaron para la Academia en años anteriores muriendo durante finales del siglo XVIII como es el caso de Antonio de Sancha, Joaquín Ibarra, Santiago Torrado y Manuel Serrano.

Los que sí hemos podido observar es la repetición del tipo de encuadernación (rústica, pergamino, holandesas, tafilete, pasta jaspeada o española) y muy pocas de lujo o con marcas heráldicas destinadas a regalos a personalidades de la realeza y de la nobleza.

Las obras más encuadernadas fueron gramáticas, vocabularios, ortografías y diccionarios además de oraciones por el nacimiento o muerte de algún miembro de la familia real, algún Quijote.

Encontramos encuadernadores que realizaron pequeños encargos como Manuel Serrano con sesenta y siete volúmenes en sus cuatro encargos entre 1755 y 1758; Santiago Torrado con un único encargo en 1761 por la encuadernación de nueve volúmenes; Gabriel de Sancha con un encargo en 1792 realizando ciento cuarenta y seis encuadernaciones, muchas de ellas en pasta española y jaspeada; Rafael Sánchez de Aguilera tuvo solo un encargo en 1797 por la encuadernación de seis juegos del Quijote grande; Ramón Antonio de Herrera realizó dos encargos en 1798 encuadernando sesenta y seis volúmenes de diccionarios y Quijotes en pasta; Jaime Vidal tuvo dos encargos en 1798 realizando ciento sesenta y cinco encuadernaciones del Diccionario y de la Gramática.

También localizamos y documentamos otros encargos de gran número de ejemplares como la producción de Joaquín Ibarra con cinco encargos entre 1771 y 1779 , con un total de dos mil ciento ochenta y seis volúmenes, entre los que cabe destacar los setecientos noventa y dos ejemplares de la Oración por el nacimiento del Infante Carlos Clemente de Borbón en su primer encargo de 1771; Miguel y sobre todo Miguel y Manuel Millana tuvieron encargos durante el siglo XVIII, en concreto entre 1796 y 1799 , con un total de dos mil cuatrocientas setenta y una encuadernaciones predominando los diccionarios, gramáticas y Quijotes; Hilario Clarós recibió encargos entre 1797 y 1799 sobresaliendo los diccionarios, gramáticas y ortografías, mayormente recubiertas de pergamino, haciendo un total de dos mil seiscientas cuarenta y tres encuadernaciones; y Ramón Matute durante el siglo XVIII tuvo tres encargos, en concreto entre 1798 y 1799, destacando la encuadernación de Quijotes, diccionarios, ortografías, gramáticas y Premios de la Academia, realizando un total de seiscientas sesenta y siete encuadernaciones, en su mayoría en pasta.

\section{Conclusiones}

Una vez realizado el estudio de los datos extraídos de los libros de cuentas, actas... y realizando también comparativas con trabajos ya realizados en otras Academias, encontramos que algunos de los encuadernadores trabajaron simultáneamente para diferentes Academias realizando encuadernaciones similares (rústica, holandesas pasta española, jaspeada, pergamino...), empleando los mismos tipos de estructuras constructivas (costura a punto seguido, punto salteado, diente de perro, costura de un cuadernillo...). También hemos podido encontrar similitud en los precios de unos encuadernadores y otros, tanto para la misma obra en la Academia como con obras diferentes en otras Academias, aunque igualmente observamos que los precios los encuadernadores de primera fila, en comparación con sus colegas coetáneos, eran algo superiores.

El trabajo nos ha permitido localizar, analizar y estudiar la producción de cada uno de los encuadernadores que trabajaron para la Real Academia en este periodo de la segunda mitad del siglo XVIII, localizando encargos de encuadernadores reconocidos como Antonio y Gabriel de Sancha, 
Joaquín Ibarra, los hermanos Millana y también de encuadernadores de los que no se tenían referencias como Hilario Clarós, Ramón Matute, Manuel Serrano, Santiago Torrado, Rafael Sánchez de Aguilera, Ramón Antonio de Herrera y Jaime Vidal y además realizar el análisis de sus encuadernaciones, identificando elementos decorativos que nos ayudarán a conocer e identificar sus encuadernaciones en otras instituciones.

\section{Notas}

(1) Habla sobre la importancia de Antonio de Sancha en la renovación de las encuadernaciones españolas, y el interés personal de Carlos III.

(2) Archivo RAE. Cuentas del año 1761. Sig. 120/14/1/1r.

(3) La Academia de la Crusca, fundada en 1583 en Florencia, es la institución lingüística más importante de Italia. Su diccionario recoge la variedad literaria del italiano antiguo. Vocabolario degli Accademici della Crusca. Quarta impressione. In Firenze: apresso Domenico Maria Manni, 1729-1738. Sig. RAE D 0-2-1 a 6.

(4) Archivo RAE. Cuentas del año 1774. Sig. 121/23/8/1v.

(5) Archivo RAE. Cuentas del año 1777. Sig. 122/26/2/1r.

(6) Archivo RAE. Cuentas del año 1778. Sig. 122/35/1/1r.

(7) Archivo RAE. Cuentas del año 1778. Sig. 123/4/3/1r.

(8) Este ducado fue creado por Alfonso XIII, rey de España el 22 de febrero de 1893, siendo la primera titular María del Rosario Pérez de Barradas y Fernández de Córdoba, XIII marquesa de Peñaflor.

(9) Archivo RAE. Cuentas del año 1794. Sig. 2634/1/27/1v.

(10) Juan de Sahagún de la Mata Linares (1755-1797), I conde del Carpio, oficial cercano a Gaspar Melchor de Jovellanos. Casado en 1775 con María Rita Barrenechea y Morante (1757-1795). El conde adquirió el título de marqués de la Solana antes de la muerte de su mujer en 1795. Fue alcalde de la Real Audiencia de Barcelona y ministro del consejo de Órdenes. Fue académico honorario de la Real Academia Española en 1794, supernumerario en 1795 y académico de número en 1797 , ocupando la silla U.

(11) Clemente Peñalosa y Zúñiga (1751-1804). Fue canónigo en Valencia en la década de 1780; perteneció a la Sociedad Económica de Segovia y de la Academia de la Historia de Valladolid en 1794. En 1795 fue nombrado académico honorario de la Real Academia Española y en 1792 académico honorario de la Real Academia de Bellas Artes de San Fernando.

(12) Archivo RAE. Cuentas del año 1795. Sig. 2634/1/28/1v.

(13) Joaquín Juan de Flores y la Barrera (1759-1812). Jurista y militar, fue elegido en la Real Academia Española académico honorario en 1795, supernumerario en 1796 y académico de número en 1798, ocupando la silla $\mathrm{B}$. Fue admi-tido en la Real Academia de derecho Español y Público en 1780, miembro de la Real Sociedad Económica Matritense de Amigos del País, de la Real Academia de la Historia y a la de Buenas Letras de Sevilla.

(14) Archivo RAE. Cuentas del año 1795. Sig. 2634/2/4/1v.

(15) Juan Crisóstomo Ramírez Alamanzón (ca.1795-1814). Fue canónigo cisterciense, bibliotecario mayor de la Biblioteca Real, además fue académico supernumerario de la Real Academia de la Historia en 1803 y académico honorario en la Real Academia de Bellas artes de San Fernando en 1806; fue elegido académico honorario en 1790 , supernumerario en 1791 y académico de número en 1794, ocupando la silla M, siendo el primer bibliotecario de la Academia Española, entre los años 1794 y 1808.

(16) Archivo RAE. Cuentas del año 1795. Sig. 2634/2/5/1v.

(17) Archivo RAE. Cuentas del año 1795. Sig. 2634/2/6/1v.

(18) Archivo RAE. Cuentas del año 1795. Sig. 2634/2/7/1v.

(19) Archivo RAE. Cuentas del año 1796. Sig. 2634/2/8/1v.

(20) Manuela Contera Mañas (ca. 1722-1805). Fue la segunda mujer del impresor y librero Joaquín Ibarra, toma a su muerte en 1785 las riendas del negocio, teniendo como regente de la imprenta a Rafael Sánchez Aguilera, en la calle Gorguera, manteniendo Manuela el título de impresora de la Real Academia. Con su muerte continua con la imprenta su hija Manuela Justa Ibarra Contera, y después su hijo, hasta la desaparición de la imprenta en 1836.

(21) Archivo RAE. Cuentas del año 1796. Sig. 2634/3/1/1v.

(22) Archivo RAE. Cuentas del año 1796. Sig. 2634/2/9/1v.

(23) Archivo RAE. Cuentas del año 1796. Sig. 2634/2/10/1v.

(24) Archivo RAE. Cuentas del año 1796. Sig. 2634/2/11/1v.

(25) Archivo RAE. Cuentas del año 1796. Sig. 2634/2/12/1v.

(26) Archivo RAE. Cuentas del año 1796. Sig. 2634/3/5/1v.

(27) Archivo RAE. Cuentas del año 1797. Sig. 126/11/1/1r.

(28) Archivo RAE. Cuentas del año 1792. Sig. 125/19/1/1r.

(29) López de la Huerta, José. Examen de la posibilidad de fixar la significacion de los sinónimos de la lengua castellana. En Viena: en la Imprenta de Ignacio Alberti, 1789. Sig. 23-X-34.

(30) Gattel, Claude Marie. Nouveau Dictionnaire espagnol et françois, françois et espagnol, avec l'interpretation latine de chaque mot... Lyon: chez Bruyset freres, 1790. T I-IV. Sig. 23-XII-2(I-IV).

(31) Encuadernación en pasta española, cuyas tapas están decoradas con una orla de tres hilos gofrados. Los cuadernillos están unidos entre sí mediante seis nervios de cordel de fibra vegetal, con ocho estaciones de costura y un cosido a punto salteado. El papel de guardas es del tipo marmoleado modelo plegado español de color marrón, verde, rojo y negro. En el lomo, los nervios están decorados con una paleta de hilos inclinados y los siete entrenervios, con una plancha compuesta de una flor con hojas y dos grandes frutos, motivos florales y vegetales en las esquinas y en los laterales verticales, y relleno de circulitos, círculos divididos en cuartos y rombos. Está encuadrada con paletas de dos hilos en los lados horizontales, y uno dentado en las verticales. Observamos una paleta de motivos florales entrelazados con tallos en la parte superior, y dos veces en la inferior. En el segundo entrenervio se aprecia un tejuelo de piel granate con la leyenda «BIBLIA / EN ESPAÑOL», y en el tercer entrenervio, otro de piel verde con la leyenda «ANT. TESTAM. / TOMO I-V》 —según el tomo-, todo ello dorado. Los cortes están teñidos de rojo, las cabezadas son de color azul y amarillo alternados, y la cinta de registro es de tela azul. Los cantos y las cofias están decorados con una rueda dorada de hilos lisos y punteados alternados e inclinados. El estado de conservación no es uniforme con roturas en las esquinas, rozaduras, y pérdida de las cabezadas en los tomos I y III. Dimensiones: $320 \times 240 \times 67$ mm (T1); 57 mm (T2); 60 $\mathrm{mm}$ (T3); 63 mm (T4); 58 mm (T5). 
(32) Archivo RAE. Cuentas del año 1778. Sig. 123/6/8/1v.

(33) Archivo RAE. Cuentas del año 1795. Sig. 2634/8/1 y 2634/8/2/1v-r/2v-r/3v-r/4v-r.

(34) Pedro de Silva y Sarmiento de Alagón (1742-1808). Fue el octavo director de la Academia Española, desde 1802 hasta 1808. Ostentó el cargo de bibliotecario mayor del rey y miembro de la Sociedad Económica Vascongada y Cantábrica y de las academias de Nobles Artes de Madrid (1768) -ahora de las Bellas Artes de San Fernandoy de Valencia, socio de la Real Sociedad Económica de Madrid de Amigos del País (1775) y de la Real Sociedad Económica de Sevilla de Amigos del País (1778), socio de la American Academy of Arts and Sciences de Massachusetts (1789), académico de la Real Academia de Medicina de Barcelona (1796) y socio de la Sociedad Cantábrica (1798); colaboró en las ediciones del Diccionario de $1780,1783,1791$ y 1803 . Fue nombrado académico de número en 1776 ocupando la silla $Z$.

(35) Archivo RAE. Cuentas del año 1796. Sig. 126/5/10/2r.

(36) Archivo RAE. Cuentas del año 1797. Sig. 126/11/2/1r.

(37) Encuadernación realizada en pasta española, sin decoración en las tapas. Los cuadernillos están unidos mediante dos nervios de tiras de piel y cuatro estaciones de costura, con un cosido a punto salteado. El papel de guardas es del tipo marmoleado modelo plegado español gris verdoso, magenta y azul. El lomo es liso, con cinco entrenervios separados por una paleta de dos hilos. Los entrenervios están decorados con un florón de dos círculos con un rombo central, y las bandas horizontales están realizadas con una paleta de circulitos y otra de motivos con forma de cortina. En el segundo entrenervio apreciamos un tejuelo de piel ocre con la leyenda "GRAMATICA / CASTELLANA», todo ello dorado. Las cabezadas son de papel, y los cortes está moteados de marrón. En cuanto al estado de conservación apreciamos rozaduras en todas partes y roturas en el papel de los cajos de las guardas; el diseño del lomo está realizado de forma descuidada, con los diseños torcidos, lo que denota la producción en serie de grandes cantidades de libros, destinados a la venta al por menor. Dimensiones: $156 \times 109 \times 34 \mathrm{~mm}$.

(38) Archivo RAE. Cuentas del año 1797. Sig. 126/11/4/1r.

(39) Archivo RAE. Cuentas del año 1798. Sig. 126/23/3/1r.

(40) Archivo RAE. Cuentas del año 1798. Sig. 126/23/5/1r.

(41) Archivo RAE. Cuentas del año 1798. Sig. 126/23/8/1r.

(42) Archivo RAE. Cuentas del año 1798. Sig. 126/23/10/1r

(43) Archivo RAE. Cuentas del año 1799. Sig. 126/23/15/1r

(44) Archivo RAE. Cuentas del año 1799. Sig. 126/35/5/1r.

(45) Archivo RAE. Cuentas del año 1799. Sig. 126/35/7/1r.

(46) Archivo RAE. Cuentas del año 1799. Sig. 126/35/9/1r.

(47) Archivo RAE. Cuentas del año 1797. Sig. 126/11/3/1r.

(48) Archivo RAE. Cuentas del año 1798. Sig. 126/23/4/1r.

(49) Archivo RAE. Cuentas del año 1798. Sig. 126/23/9/1r.

(50) Archivo RAE. Cuentas del año 1798. Sig. 126/23/12/1r

(51) Archivo RAE. Cuentas del año 1798. Sig. 126/23/13/1r

(52) Archivo RAE. Cuentas del año 1799. Sig. 126/35/1/1r.

(53) Archivo RAE. Cuentas del año 1799. Sig. 126/35/3/1r.

(54) Archivo RAE. Cuentas del año 1799. Sig. 126/35/4/1r.

(55) Archivo RAE. Cuentas del año 1799. Sig. 126/35/8/1r.
(56) Archivo RAE. Cuentas del año 1798. Sig. 126/23/2/1r.

(57) Archivo RAE. Cuentas del año 1798. Sig. 126/23/7/1r.

(58) Archivo RAE. Cuentas del año 1798. Sig. 126/23/6/1r.

(59) Archivo RAE. Cuentas del año 1798. Sig. 126/23/14/1r.

(60) Archivo RAE. Cuentas del año 1798. Sig. 126/23/11/1r.

(61) Archivo RAE. Cuentas del año 1799. Sig. 126/35/2/1r.

(62) Encuadernación realizada en pasta española, con tapas libres de decoración. Los cuadernillos están unidos mediante dos nervios de cordel de fibra vegetal y cuatro estaciones de costura, y una costura a punto salteado. E papel de guardas es del tipo marmoleado de gotas de colores naranja, verde y azul. La encuadernación carece de cabezadas. El lomo es liso, con cinco entrenervios libres de decoración. Los nervios están simulados mediante una paleta dorada de $S$ cursiva enlazada formando olas. El tejuelo es de piel granate, con la leyenda "CO-LEECCION / DE PREMIOS» (sic.), flanqueado en las bandas horizontales por una paleta dora-da de tres hilos. Su estado de conservación es aceptable, con rozaduras en lomo y puntas, y leves pérdidas de decoración dorada. Dimensiones: 151 × 95 × 28 mm.

(63) Archivo RAE. Cuentas del año 1799. Sig. 126/35/6/1r.

\section{Referencias}

Blas Benito, Javier (1998). Pascual Carsí y Vidal, encuadernador de Carlos IV y de su Real Imprenta. // Encuadernación de Arte. 11 (1998) 33-46.

Carpallo Bautista, Antonio; Blázquez Márquez, Alejandro (2019). Fuentes archivísticas del encuadernador Antonio de Sancha en la Real Academia Española durante la segunda mitad del siglo XVIII. // Revista Interamericana de Bibliotecología. 42:4 (2019) [en prensa].

Carpallo Bautista, Antonio; Flores Hernández, Yohana Yessica; Moro Pajuelo, Marisa (2018). Recuperación y análisis de los fondos archivísticos de la Real Academia de Bellas Artes de San Fernando. El taller de encuadernación de Joaquín Ibarra. // Ibersid. 12:2 (2018) 91-96.

Carpallo Bautista, Antonio; Flores Hernández, Yohana Yessica; Burgos Bordonau, Esther (2018). El taller del encuadernador Pedro Martínez en la sociedad madrileña de finales del siglo XVIII y primeros del XIX: el caso de la Real Academia de Bellas Artes de San Fernando. // Información, Cultura y Sociedad. 38 (2018) 129-146.

Carpallo Bautista, Antonio; Flores Hernández, Yohana Yessica; Moro Pajuelo, Marisa (2019a). Los fondos archivísticos de la Real Academia de Bellas Artes de San Fernando: el librero y encuadernador Francisco de Guzmán. // Revista Investigación Bibliotecológica: archivonomía, bibliotecología e información. 33:78 (2019) 29-46.

Carpallo Bautista, Antonio; Flores Hernández, Yohana Yessica; Moro Pajuelo, Marisa (2019b). La historia de la Real Academia de Bellas Artes de San Fernando a través de su documentación de archivo: los encuadernadores José Herrera y Juan Moreno Salgado. // Bulletin Hispanique. 121:2 (2019) 711-724

Castañeda y Alcover, Vicente (1934). Notas referentes a los precios de las encuadernaciones en España (siglos XVIXIX). // Boletín de Bibliotecas y Bibliografía, I:2 (1934) 157-164.

Castañeda y Alcover, Vicente (1958). Ensayo de un diccionario biográfico de encuadernadores españoles. Madrid: Maestre, 1958.

Espejo Pérez, Álvaro; Carpallo Bautista, Antonio (2020). Juan Pérez, Librero-Encuadernador de la Real Academia

Blázquez Márquez Alejandro; Carpallo Bautista, Antonio. La Real Academia Española y su relación con los encuadernadores de la segunda mitad del siglo XVIII: documentación de archivo. // Ibersid. 14:1 (en.-jun. 2020) 41-54. ISSN 1888-0967. 
Española. // Bulletin of Spanish Studies. 97:1 (2020) [en prensa].

Flores Hernández, Yohana Yessica (2016). Estudio, catalogación y digitalización de las encuadernaciones artísticas de la Real Academia de Bellas Artes de San Fernando. Tesis Doctoral defendida en 2016 en la Universidad Complutense de Madrid.

Flores Hernández, Yohana Yessica; Carpallo Bautista, Antonio (2017). Los encuadernadores de la Real Academia de Bellas Artes de San Fernando // RUIDERA, Revista de Unidades de Información. 12 (2017) 255-263.

Flores Hernández, Yohana Yessica; Carpallo Bautista, Antonio; Burgos Bordonau, Esther (2018). El taller de Sancha en la Real Academia de Bellas Artes de San Fernando. // Titivillus. 4 (2018) 39-62.

Flores Hernández, Yohana Yessica; Carpallo Bautista, Antonio; Moro Pajuelo, Marisa (2019). El librero y encuadernador Manuel Millana en la Real Academia de Bellas Artes de San Fernando // Revista General de Información y Documentación. 29:1 (2019) 87-106.

García González, María; Carpallo Bautista, Antonio; Martín Escudero, Fátima (2018). Encuadernadores madrileños en el siglo XVIII: la familia Menoyre. // Actas de las II Jornadas de Estudiantes de Ciencias de la Documentación: Tendiendo puentes. Madrid: UCM, 2018. 84-91.

López Castán, Ángel (1986). La encuadernación madrileña y la comunidad de mercaderes y encuadernadores de libros de la Corte en el siglo XVIII. // Villa de Madrid. XXIV:89-90 (1986) 41-63.

López Serrano, Matilde (1937). La encuadernación en Madrid en la primera mitad del siglo XVIII. // Archivo Español de Arte y Arqueología. 37 (1937) 1-13.

López Serrano, Matilde (1940). La encuadernación madrileña en la época de Fernando VI. // Archivo Español de Arte. 40 (1940) 27-38.

López Serrano, Matilde (1942). Libreros encuadernadores de cámara. I. Antonio Suárez. // Arte Español. XIV (1942) 714.

López Serrano, Matilde (1943). Libreros encuadernadores de cámara. II. Santiago Martín. // Arte Español, XIV (1943) 14-28.
López Serrano, Matilde. (1945a). La encuadernación madrileña durante el reinado de Carlos III. // Archivo Español de Arte. 67 (1945) 1-16.

López Serrano, Matilde. (1945b). La encuadernación española del siglo XVIII. // Gráficas. 17 (1945) 4-5, 28.

López Serrano, Matilde (1945c). El encuadernador Gabriel Gómez Martín. // Revista de Bibliografía Nacional. VI (1945) 51-72.

López Serrano, Matilde (1946a). Antonio de Sancha, encuadernador madrileño. // Revista de Bibliotecas, Archivos y Museos Municipales. 54 (1946) 269-307.

López Serrano, Matilde (1946b). Una tormenta doméstica en la familia Sancha. // Revista de Bibliografía Nacional. VII (1946) 391-399.

López Serrano, Matilde (1950). La encuadernación madrileña en la época de Carlos IV. // Archivo Español de Arte. 90 (1950) 115-131.

López Serrano, Matilde (1975). Gabriel de Sancha: editor, impresor y encuadernador madrileño (1746-1820). Madrid: Ayuntamiento, Instituto de Estudios Madrileños, 1975.

Real Academia Española (2019). Estatutos y reglamento nuevo. Madrid, 1993-2014. http://www.rae.es/sites/default/files/Estatutos_y_reglamento_nuevo.pdf (2019-0831).

Sánchez Espinosa, Gabriel (2014). Antonio y Gabriel de Sancha, libreros de la llustración, y sus relaciones comerciales con Inglaterra. // Bulletin of Spanish Studies: Hispanic Studies and Researches on Spain, Portugal and Latin America. 91:9-10 (2014) 217-259.

Zamora Vicente, Alonso (1999). Historia de la Real Academia Española. Madrid: Calpe, 1999.

Enviado: 2020-03-02. Segunda versión: 2020-05-22. Aceptado: 2020-06-04. 